\title{
Improving the velocity field in South and South-East Asia: The third round of GEODYSSEA
}

\author{
M. Becker ${ }^{1}$, E. Reinhart ${ }^{1}$, Soeb Bin Nordin ${ }^{1}$, D. Angermann ${ }^{2}$, G. Michel $^{2}$, and C. Reigber ${ }^{2}$ \\ ${ }^{1}$ Bundesamt für Kartographie und Geodäsie, Frankfurt am Main, Germany \\ ${ }^{2}$ GeoForschungsZentrum, Potsdam, Germany
}

(Received January 17, 2000; Revised June 14, 2000; Accepted June 14, 2000)

\begin{abstract}
In the framework of the GEODYnamics of South and South-East Asia (GEODYSSEA) project a network of 42 stations was observed by GPS during two field campaigns in 1994 and 1996. BKG and GFZ realized a third observation of the complete network in 1998. The data was analyzed independently by two analysis centers and a precision of the coordinate solutions was found to be $4-7 \mathrm{~mm}$ for the horizontal, and $10 \mathrm{~mm}$ for the vertical component. Subsequently, these campaign solutions were merged into one unique solution, which was accurately mapped into the International Terrestrial Reference Frame of 1997 (ITRF97). The global accuracy of this solution with respect to ITRF97 is of the order of $10 \mathrm{~mm}$, while the resolution of the relative horizontal velocities is estimated to be at the level of $2-3 \mathrm{~mm} / \mathrm{yr}$. Comparison of the new solution with the previously published GEODYSSEA solution indicates, that improved results for the motion of Sundaland, South China and the overall deformation in the area could be found. Improvements are due to the increased time span and due to a better connection to and the advances in the ITRF reference frame. The new set of coordinates and velocities is used as the basis for scientific interpretations, which have been and will be published in separate papers.
\end{abstract}

\section{Introduction}

The GEODYnamics of South and South-East Asia (GEODYSSEA) project (Wilson et al., 1998; Wilson et al., 2000) was initiated as a common EC-ASEAN project in order to investigate the complex geodynamic processes in SouthEast Asia. They result from the convergence and the collision of the Eurasian, Philippine Sea, Indian, and Australian plates with relative velocities of up to $0.1 \mathrm{~m}$ per year. A detailed description of the geodynamics of South-East Asia can be found in Rangin et al. (1990).

Former investigations in South-East Asia, using GPS for regional and also for local measurements, were mainly limited to one national territory. Geodetic and geodynamic activities in South-East Asia were concentrated in the past among others on the Sumatra subduction zone (Prawirodirdjo et al., 1997), the Java trench (Tregoning et al., 1994), Irian Jaya (Puntodewo et al., 1994) and parts of the Philippine fault (Duquesnoy et al., 1994). The GEODYSSEA project, on the contrary, aimed at determining the tectonic motions homogenously for the entire region of South-East Asia. The result is a uniform representation of the kinematics in the global reference frame ITRF and a first order reference system in which smaller networks and regional studies can be merged. The project was carried out by a large international group of participants including 22 official authorities and institutions of 14 different Asian and European countries. After the official end of the project in 1997, the Bundesamt für Kartographie und Geodäsie (BKG, the former IfAG) and the

Copy right(C) The Society of Geomagnetism and Earth, Planetary and Space Sciences (SGEPSS); The Seismological Society of Japan; The Volcanological Society of Japan; The Geodetic Society of Japan; The Japanese Society for Planetary Sciences.
GeoForschungsZentrum Potsdam (GFZ) decided to spend their own resources for a third campaign, analogous to the two other GEODYSSEA campaigns, for verification of results and in order to increase the accuracy. This paper describes the geodetic results of the project based on the combined analysis of the three GPS campaigns in 1994, 1996, and 1998. A new solution for station coordinates and velocities was calculated taking into account all campaign results and additional permanent stations of the International GPS Service (IGS) tracking network (Beutler et al., 1998).

\section{The GEODYSSEA Network}

The GEODYSSEA network (Fig. 1) covers an area of more than $4000 \times 4000 \mathrm{~km}$ and includes approx. 42 observation stations throughout South and South-East Asia. The stations were selected especially for the project in order to ensure a good covering of all important tectonic blocks in the area. Prior to the first measurements the stations were monumented in parent-rock, if possible, using specially designed bolts (see figure 1 in Reinking et al., 1995) which guarantee a repeatable centering accuracy of $0.2 \mathrm{~mm}$. This work was done by teams, each consisting of one geodetic engineer and one geologist or geophysicist from the EU countries and the respective ASEAN partner country, who measured simultaneously, using GPS, at each station a local ground network consisting of the main GEODYSSEA marker and 3 witness marks. In case of a destruction of the main marker the witness marks will allow to still use the site for velocity estimation.

While in the highly developed industrial countries more and more permanent GPS networks are being established, the logistic and infra-structural problems of the South-East Asian countries at the beginning of the GEODYSSEA project 


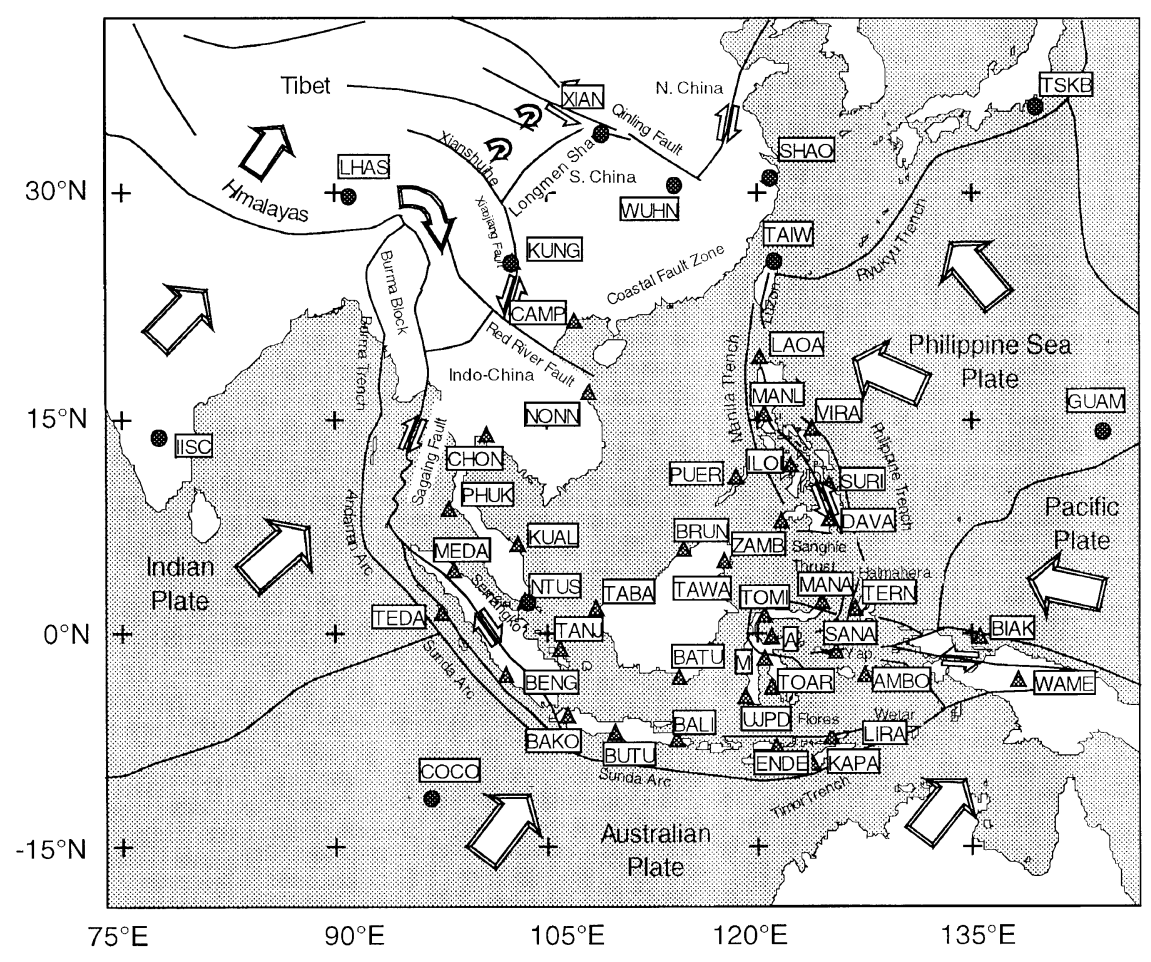

Fig. 1. The GEODYSSEA network (triangles), GPS permanent stations (circles), and plate boundaries of the NUVEL1A-NNR model in South-East Asia. Arrows indicate the overall motion of the plates.

allowed us to observe a network of this dimension only by geodetic campaigns. The measurements were designed appropriately so as to be able to respond to the problems occurring with epoch-measurements for the interpretation of the results, e.g. due to transient effects in the position, such as those induced by earthquakes, or due to time variations and episodic motions of the stations. In order to minimize the influences of errors in the reference system, the satellite orbits, and the ionosphere, all main stations in the GEODYSSEA network were observed simultaneously and continuously for a period of five days. The typical record and analysis of one campaign includes 220 station days with $24 \mathrm{~h}$ sessions.

As there were no GPS permanent stations of the IGS in the region of investigation it was necessary to use the nearest permanent stations for the connection to the ITRF. Thus, the data of four stations of the Australian Survey and Land Information Group (AUSLIG) on the Australian Plate were added. The six nearest IGS stations, Kitab (Uzbekistan), Taipei (Taiwan), Tsukuba (Japan), Cocos Island, Tidbinbilla, and Yarragadee (both in Australia) were selected from the IGS tracking network. The last campaign in 1998 had new stations available, among others especially Chinese stations, and so significantly more permanent stations with known ITRF coordinates could be included. This led to a significant increase of the reliability of the ITRF connection (Angermann and Becker, 2000), as seen in Fig. 1. In addition, the data of 26 stations of the Asia Pacific Regional Geodetic Project 1997 (APRGP97) (Luton et al., 1998; AUSLIG, 1999) could be used. This project serves to establish a regional reference system for Asia, South-East Asia, and the Pacific and covers 66 GPS stations, eight of which being GEODYSSEA stations and about 30 being IGS stations.
For all three observation campaigns during the project, BKG and GFZ used only Trimble 4000 SSE/SSi GPS receivers with geodetic antennas in order to avoid problems that may occur when different receiver and antenna types are combined, see also (Angermann and Becker, 2000). The data delivered by AUSLIG and the IGS were collected with TurboRogue and Ashtech receivers in connection with Dorne Margolin antennas. The first GEODYSSEA-94-GPS campaign took place from November 28th through December 2nd, 1994, it was repeated twice, from April 18th through 22nd, 1996, and from November 19th through 23rd, 1998. Fortunately the loss of data during all three campaigns in consequence of receiver breakdown, observational errors, and logistic problems can practically be neglected. Problems were only caused by destruction of stations, but between 1994 and 1998 only two stations (BOSO, AMIT) were definitely destroyed. At two stations (BRUN, SURI) it had to be switched to one of the witness marks.

\section{Analysis of the GPS Data}

The observations of both original GEODYSSEA campaigns were analyzed by four analysis groups, DEOS (TU Delft), ENS (Paris), BKG and GFZ, each of them using their favored software and analysis strategy. The GPS software packets applied, in order, contained four of the presently best-developed systems: GIPSY-OASIS II V2.1 (Blewitt et al., 1988), GAMIT V9.4 (King and Bock, 1993), EPOS V3.0 (Angermann et al., 1997) and BERNESE V4.0 (Rothacher and Mervart, 1996). As described in Simons et al. (1998), Angermann et al. (1998), a very good convergence could be proven for the different solutions within the range of $2-5 \mathrm{~mm}$ for the horizontal, and of $8 \mathrm{~mm}$ for the vertical component. 
Table 1. Standard deviations of GEODYSSEA's epoch combined solutions by BKG and GFZ, loosely constrained networks.

\begin{tabular}{lccc}
\hline \multicolumn{1}{c}{ Epoch } & Latitude $(\mathrm{mm})$ & Longitude $(\mathrm{mm})$ & Height $(\mathrm{mm})$ \\
\hline 1994 & 4.6 & 9.1 & 13.1 \\
1996 & 3.9 & 8.6 & 14.7 \\
1997 (APRGP97, BKG) & 3.1 & 3.9 & 8.6 \\
1998 & 3.5 & 5.5 & 11.1 \\
\hline
\end{tabular}

Table 2. Standard deviations of the residuals after Helmert transformation to ITRF97 for GEODYSSEA's combined solutions by BKG and GFZ in each epoch and of the global solutions at corresponding epochs.

\begin{tabular}{|c|c|c|c|c|c|}
\hline \multirow{2}{*}{$\begin{array}{c}\text { Normal } \\
\text { Equations }\end{array}$} & \multirow{2}{*}{$\begin{array}{l}\text { No. of IGS } \\
\text { Sites used }\end{array}$} & \multirow{2}{*}{$\begin{array}{l}\text { No. of IGS } \\
\text { Sites fixed }\end{array}$} & \multicolumn{3}{|c|}{ RMS of Residuals (mm) } \\
\hline & & & North & East & Up \\
\hline BKGGFZ 94 & 5 & 2 & 19.4 & 7.5 & 11.6 \\
\hline BKGGFZ 96 & 8 & 4 & 10.6 & 13.4 & 11.5 \\
\hline BKG 97 & 16 & 9 & 4.4 & 3.7 & 10.9 \\
\hline BKGGFZ 98 & 15 & 9 & 3.8 & 3.1 & 7.7 \\
\hline SIO0778R (94) & 30 & 29 & 4.1 & 6.7 & 12.2 \\
\hline MIT0849R (96) & 42 & 39 & 2.5 & 3.4 & 12.2 \\
\hline COD0927R (97) & 46 & 42 & 4.6 & 4.7 & 11.0 \\
\hline MIT0984R (98) & 54 & 47 & 3.8 & 3.1 & 11.6 \\
\hline
\end{tabular}

For an uniform solution of all three epochs now existing, BKG and GFZ undertook a re-adjustment combining only their results with the Bernese and EPOS software. The general procedure can be characterized as follows:

- Computation of loosely constrained daily solutions using the ionosphere-free linear combination (EPOS) or QIF-ambiguity fixed observations (Bernese software),

- Estimation of tropospheric zenith path delays in 4 or $2 \mathrm{~h}$ intervals,

- $15^{\circ}$ elevation mask, $30 \mathrm{sec}$ observation rate,

- IGS antenna phase center corrections after Rothacher and Mader (1996) plus modifications for the new TRM33429.00 microcentered antenna of TRIMBLE in 1998,

- Definition of datum by fixing the combined IGS orbits and earth rotation parameters.

Fixing the ambiguities, although successful in $80 \%$ of the cases on an average, presents a great problem in the area of investigation. Due to the strong ionospheric activity with geometry free L4 residuals amounting to several meters, and, due to the well-known tracking problems with the Rogue receivers at the IGS stations (IGS, 1998), special attention had to be paid to the data correction because of the estimation of ionospheric models and of the parameter setup in the Bernese software. After several iterations, nearly $5 \%$ of the station days were found to be outliers and were excluded from the combined solution. The epoch solutions and the total solution were computed by combining the daily normal solutions of BKG and GFZ with the program ADDNEQ of the Bernese software. For this the normal equations of GFZ, available in the SINEX format, were transformed into the Bernese format and all normal equations were weighted corresponding to their internal accuracy.

\subsection{Internal network precision}

The internal network precision is often estimated using the daily repeatability of the station coordinates computed. For the GEODYSSEA-94 and -96 campaigns mean deviations of station coordinates of $3 \mathrm{~mm}$ for the latitude, $6 \mathrm{~mm}$ for the longitude, and $8 \mathrm{~mm}$ for the height have been found (cf. Simons et al., 1999). An even more rigorous check of the quality was obtained by a comparison of the four GEODYSSEA-94 and -96 solutions that were computed nearly independently by BKG, DEOS, ENS, and GFZ. The internal consistency of these solutions amounts to $2-5 \mathrm{~mm}$ for the horizontal, and $7 \mathrm{~mm}$ for the vertical component (Angermann et al., 1998). Taking additional systematic errors (reference system, residual errors of the IGS orbits, antenna phase center corrections) into account, for GEODYSSEA-94 and -96 a network accuracy of 4-7 $\mathrm{mm}$ for the horizontal, and of $10 \mathrm{~mm}$ for the vertical component (Angermann and Becker, 2000) can be assumed. In 1998 the improved quality of the IGS products for satellite orbits, earth orientation and reference network led to an increase of accuracy. Table 2 gives an overview of the internal accuracy of the epoch solutions of BKG and GFZ.

\subsection{Connections to ITRS}

The loosely constrained solutions had to be transformed into ITRF in an adequate way in order to determine coordinates and velocities within the global reference system. In the solution presented here the ITRF97 (Boucher et al., 1999) 
is used, which offers an increased number of sites with improved values for coordinates and velocities compared to the ITRF96 (Sillard et al., 1998). For the mapping into the ITRF the procedure follows the strategy of IGS for densification of the IGS polyhedron (see e.g. Davies, 1997). This means, that for each epoch of GEODYSSEA, the loosely connected network solution is combined with a global, free, weekly solution of the IGS global analysis centers, see Table 2 for the name of the solutions used. The global SINEX files and further information is available from the IGS data centers, see e.g. Noll (2000). The number of stations in the global data sets was reduced to the 52 IGS core stations.

Combining these global, loosely constrained solutions, now including the GEODYSSEA regional network, a final solution in the ITRF97, using a 6 and 3 parameter Helmert transformation on coordinates and velocities respectively of selected IGS sites, is computed. This procedure improved the datum definition of both velocities and coordinates. Table 2 also lists the residuals and rms of the Helmert transformation in each epoch that shows the improvement over the years. Accuracy is discussed in detail by Angermann and Becker (2000). As for stations with discontinuities caused by earthquakes, either two different velocities were estimated or a new point was introduced formally to only estimate one velocity for the undisturbed interval.

A comparison between the IGS station coordinates from the final GEODYSSEA solution with ITRF97 values gives mean errors within the coordinate residuals of 5,8 and $7 \mathrm{~mm}$ for latitude, longitude and height. This illustrates that the global accuracy with respect to ITRF97 amounts to be in the range of $10 \mathrm{~mm}$ for the horizontal and for the vertical station position as well. In the combined global adjustment the formal $1-\sigma$ uncertainties of station positions are in the order of $1-3 \mathrm{~mm}$ for position and about $3-5 \mathrm{~mm}$ for the height. The estimations of station velocity within ITRF97 have formal $(1-\sigma)$ uncertainties of $0.3-0.9 \mathrm{~mm} / \mathrm{yr}$ for the horizontal, and of $3 \mathrm{~mm} / \mathrm{yr}$ for the height component respectively.

\section{Results and Discussion}

The principal results of data analysis are the station velocities being computed together with the station coordinates. The final combined solution containing coordinates and velocity estimations of the GEODYSSEA points within ITRF97 is shown in Fig. 2. The formal accuracies of the global adjustment are too optimistic because of the great number of observations and the neglecting of correlation in the GPS observations. The uncertainties and corresponding error-ellipses have been rescaled by a variance factor of 7.5 to represent approximately the internal accuracy from the network repeatability of the daily solutions.

A detailed analysis of the results can be found in Michel et al. (2000) in this volume; therefore we give only a summary of the most important results. Figure 2 presents, in addition to the measured velocities, the geologic-geophysical velocities of the No-Net-Rotation (NNR) NUVEL-1A model (DeMets et al., 1994). The deviations from the model can be divided into two groups. Within the active deformation zones at plate boundaries, e.g. West of Sumatra, on Sulawesi, and/or on the Philippines, the expected motion anomalies are caused by active tectonics and motion along major faults.

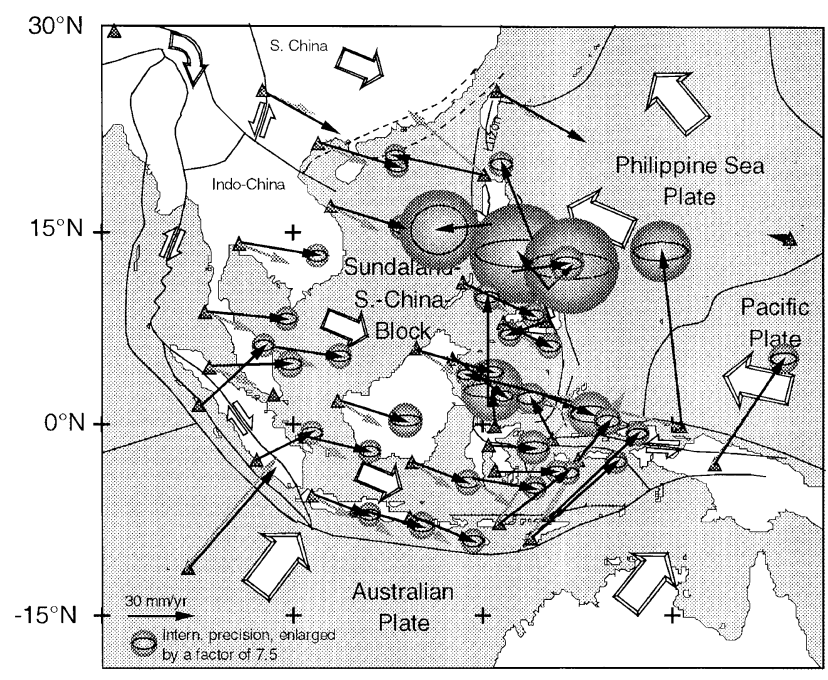

Fig. 2. Velocities of the final GEODYSSEA solution in the ITRF97 reference system (black) and NNR-Nuvel-1A vectors (gray, no error ellipses). Data of 1994, 1996, 1997 and 1997 were combined for the velocity estimation. Formal error ellipses are rescaled by a variance factor of 7.5 for a better approximation of the accuracy, cf. Section 4 .

Important new information on active plate boundaries and local deformation processes, as they have been found analyzing the two first campaigns (Simons et al., 1999; Michel et al., 1998), was confirmed. Observations with co-seismic shifting, e.g. the GEODYSSEA station on the island of Biak (BIAK), Indonesia, which moved horizontally for more than $1.2 \mathrm{~m}(0.90 \mathrm{~m} / \mathrm{yr}$ North, $0.42 \mathrm{~m} / \mathrm{yr}$ East $)$ as a consequence of an earthquake in 1996 with a magnitude of 7.4, have to be modeled by epochs as discontinued processes with variable velocity. Between 1996 and 1998 Biak moved differently with $0.09 \mathrm{~m} / \mathrm{yr}$ North and $-0.01 \mathrm{~m} / \mathrm{yr}$ East.

In another example, Surigao (SURI) on the Philippine island of Mindanao, the velocity vector significantly changed due to an earthquake. For this station a velocity change from $22 \mathrm{~mm} / \mathrm{yr}$ to $13 \mathrm{~mm} / \mathrm{yr}$ for the latitude, and from $-16 \mathrm{~mm} / \mathrm{yr}$ to $+11 \mathrm{~mm} / \mathrm{yr}$ for the longitude could be observed.

Table 3 gives the estimated accuracy for the results of each analysis. The mean values and the standard deviations of the estimated velocities from both the two first and the two last solutions with respect to the final global solution were computed. The velocities from epochs 1994-1996 have a systematic difference in the horizontal component. Scattering is also significantly higher than in epoch 1996-1998. This shows, that the accuracy estimated on the basis of repeatability, cf. Table 1 , is too optimistic. The weakness of the ITRF connection due to the lack of IGS permanent sites in the area may lead to such systematic effects and has surely influenced the solution of the two first epochs. As discussed in Angermann (1998), Angermann and Becker (2000), different ways of mapping the GEODYSSEA network onto the ITRF may lead to coordinate changes in the 10 to $20 \mathrm{~mm}$ range and may cause a distortion or rotation of the network. With the 1997 and 1998 data added, the increased time span and the increased number of permanent sites used for the mapping, these systematic effects are minimized, cf. Section 5 for further remarks. 
Table 3. Comparison of mean values and standard deviations of the velocities of the combined BKG/GFZ solutions for two separate intervals with respect to the global solution over all years. In addition the individual solutions of BKG and GFZ over all years are compared in the last line (mm/yr).

\begin{tabular}{cccccccc}
\hline & \multicolumn{3}{c}{ Velocity differences } & & \multicolumn{3}{c}{ Std. dev. of velocities } \\
\cline { 2 - 4 } \cline { 6 - 8 } Epoch & Latitude & Longitude & Up & & Latitude & Longitude & Up \\
\hline $1994-1996$ & -7.5 & 1.3 & 3.3 & & 3.1 & 7.8 & 19.6 \\
$1996-1998$ & 2.9 & -0.5 & -0.1 & & 1.0 & 1.3 & 5.9 \\
BKG-GFZ & 1.3 & -0.8 & -7.4 & & 1.5 & 2.4 & 6.1 \\
\hline
\end{tabular}

Table 4. GPS-velocities of Sundaland sites from the combined GEODYSSEA campaigns from 1994 to 1998 in the ITRF97 reference frame, Epoch 1996.9. Formal uncertainties are rescaled by a variance factor of 7.5 for a better approximation of the accuracy, cf. Section 4 .

\begin{tabular}{|c|c|c|c|c|c|c|}
\hline Site & $\begin{array}{c}\text { Latitude } \\
\left({ }^{\circ}\right)\end{array}$ & $\begin{array}{c}\text { Longitude } \\
\left({ }^{\circ}\right) \\
\end{array}$ & $\begin{array}{c}\text { North-velocity } \\
(\mathrm{mm} / \mathrm{yr})\end{array}$ & $\begin{array}{c}\text { Sigma } \\
(\mathrm{mm} / \mathrm{yr})\end{array}$ & $\begin{array}{c}\text { East-velocity } \\
(\mathrm{mm} / \mathrm{yr})\end{array}$ & $\begin{array}{c}\begin{array}{c}\text { Sigma } \\
(\mathrm{mm} / \mathrm{yr})\end{array} \\
\end{array}$ \\
\hline BAKO & -6.49105 & 106.8489 & -9.3 & 1.9 & 27.2 & 3.8 \\
\hline BALI & -8.14746 & 114.68002 & -12.3 & 1.9 & 30.7 & 3.8 \\
\hline BATU & -3.86716 & 114.79119 & -9.8 & 1.9 & 26.5 & 4.1 \\
\hline BUTU & -7.63518 & 110.20817 & -8.2 & 2.2 & 32.7 & 4.1 \\
\hline $\mathrm{CHON}$ & 13.12053 & 101.0447 & -6.0 & 1.9 & 38.2 & 3.5 \\
\hline KUAL & 5.31888 & 103.13914 & -7.5 & 1.9 & 35.9 & 3.8 \\
\hline NONN & 16.00364 & 108.26339 & -10.1 & 1.9 & 35.9 & 3.8 \\
\hline PHUK & 7.75906 & 98.30359 & -4.1 & 1.9 & 35.0 & 3.5 \\
\hline PUER & 10.08577 & 118.8514 & -16.0 & 1.9 & 35.7 & 3.8 \\
\hline TABA & 0.86279 & 108.89085 & -10.2 & 1.9 & 33.3 & 5.7 \\
\hline TANJ & -1.88066 & 106.17591 & -7.9 & 1.9 & 31.1 & 3.5 \\
\hline
\end{tabular}

The velocities computed separately solely from the solution of BKG and GFZ show a good agreement for the horizontal components. The vertical component may eventually contain systematic components from the modeling (among others antenna phase center corrections and troposphere).

A new and important finding from the two first GEODYSSEA campaigns with far-reaching consequences for interpretation of tectonics in South-East Asia was the definition of the Sundaland block that behaves differently from the Eurasian plate (Wilson et al., 1998). The formerly observed motion of the Sundaland block, which adopted a twodimensional block velocity model for 12 stations (NONN, CHON, KUAL, MEDA, PHUK, TABA, TANJ, BATU, BAKO, UJPD, BUTU, BALI) described by an Euler vector, has to be modified after including the data of 1998. Using the velocities of the Sundaland sites listed in Table 4, plus the ITRF97 velocities of Shanghai, Wuhan, Xian and Singapore, the Euler vector shows a polar rotation of about $0.34 \pm 0.01^{\circ} / \mathrm{Ma}$ with a pole position of $59.7^{\circ} \pm 2.8^{\circ} \mathrm{N}$ and $102.7^{\circ} \pm 3.9^{\circ} \mathrm{W}$ in the ITRF97.

These new values differ slightly, but significantly, from the ones previously published (Chamot-Rooke et al., 1998; Michel et al., 1998). They do confirm the differential motion of the Sundaland block versus Eurasia and are more reliable due to the better connection to the ITRF in the new solution as compared to the data of the first two campaigns alone. For a detailed discussion and comparisons to the results of other project carried out in this region cf. Michel et al. (2000).

\section{Outlook}

In the future we may expect further improvements of the results presented here from a global solution from 1994 to 1998. Thanks to the initiative of the IGS analysis centers towards a re-computation of all GPS orbits from the beginning of the IGS on the basis of the ITRF97 coordinates and velocities, a re-adjustment of the campaigns of 1994 and 1996 can be made in a uniform reference system. This would surely further enhance the internal and external accuracy of these first two solutions. Improvement of orbit accuracy for the periods of the first two campaigns can be gained by adding some selected GEODYSSEA stations for the orbit computation. This method would result in a densification of the poor network of reference stations of the years 94 and 96.

Future geodetic investigations will increasingly concentrate on selected parts or regions of the original GEODYSSEA project area using networks of permanent stations being set up in South-East Asia. This allows a further, yet less expensive control of very interesting sections of the GEODYSSEA network. Local studies, especially at plate boundaries and at selected fault zones exist already in connection with the campaigns observed up to now. First results are published e.g. in Becker et al. (1998a,b), Simons et al. (2000), Walpersdorf et al. (2000) and further publications are forthcoming.

Acknowledgments. We gratefully appreciate having at our disposal data of APRGP97 and from the Australian permanent stations 
by Australian Land Information Group, from the SULAWESI97 campaign by the University of Delft, from the WING network in MANILA from T. Kato and from the Malay stations 1998 by the Department of Surveying and Mapping Malaysia. Thanks to our colleagues Claude Rangin, Christophe Vigny and Andrea Walpersdorf, Ecole Normale Supérieure, Paris, as well as to Boudewijn Ambrosius, Ron Noomen and Wim Simons, Delft Institute of Earth Oriented Space Research for the many fruitful discussions during analysis and interpretation of the data. Many thanks to Jürgen Klotz, GFZ, for his effort during the GEODYSSEA campaigns.

\section{References}

Angermann, D., The datum definition of the GEODYSSEA network, in The Geodynamics of $S$ and SE Asia (GEODYSSEA) Project, edited by $\mathrm{P}$. Wilson and G. W. Michel, Scientific Technical Report 98/14, pp. 113119, Potsdam, 1998.

Angermann, D. and M. Becker, Untersuchungen zu Genauigkeit und systematischen Effekten in großräumigen GPS-Netzen am Beispiel von GEODYSSEA, Zeitschr. f. Verm. Wesen, 125/3, 88-95, 2000.

Angermann, D., G. Baustert, R. Galas, and Z. H. Zhu, EPOS.P.V3 (earth parameter \& orbit system), Software user manual for processing of GPS networks, 97/14, GFZ Potsdam, 1997.

Angermann, D., M. Becker, W. J. F. Simons, and A. Walpersdorf, The solutions of the European analysis centers for the GEODYSSEA 94/96 GPS campaigns, in The Geodynamics of $S$ and SE Asia (GEODYSSEA) Project, edited by P. Wilson and G. W. Michel, Scientific Technical Report 98/14, pp. 103-112, Potsdam, 1998.

AUSLIG, http: / / www. permcom.auslig.gov.au, Canberra, 1999.

Becker, M., R. L. Almeda, M. Aurelio, C. Boonphakdee, M. Kasser, and P. Neumaier, Data evaluation of the 1994 MINDANAO GPS-campaign, GEODYSSEA, in The Geodynamics of $S$ and SE Asia (GEODYSSEA) Project, edited by P. Wilson and G. W. Michel, Scientific Technical Report 98/14, pp. 162-167, Potsdam, 143-152, 1998a.

Becker, M., P. Neumaier, E. Reinhart, H. Seeger, N. Trong Yem, C. C. Duong, L. To, and D. T. Tran, GPS measurements of crustal movements at the red river fault in Vietnam, in The Geodynamics of $S$ and SE Asia (GEODYSSEA) Project, edited by P. Wilson and G. W. Michel, Scientific Technical Report 98/14, pp. 184-190, Potsdam, 1998b.

Beutler, G., M. Rothacher, T. Springer, J. Kouba, and R. E. Neilan, The international GPS service (IGS): An interdisciplinary service in support of Earth sciences, 32nd COSPAR Scientific Assembly, Nagoya, Japan, July 12 to 19,1998 , pp. 27-50, 1998 .

Blewitt, G., W. G. Melbourne, W. I. Bertiger, T. H. Dixon, P. M. Kroger, S. M. Lichten, T. K. Meehan, R. E. Neilan, L. L. Skrumeda, C. L. Thornton, S. C. Wu, and L. E. Young, GPS geodesy with centimeter accuracy, in Lecture Notes in Earth Sciences, edited by E. Groten and R. Strauss, Springer-Verlag, New York, 1988.

Boucher, C., Z. Altamimi, and P. Sillard, The 1997 International Terrestrial Reference Frame (ITRF97), IERS technical note No. 27, Observatoire de Paris, 1999.

Chamot-Rooke, N., X. Le Pichon, C. Rangin, P. Huchon, M. Pubellier, C. Vigny, and A. Walpersdorf, Sundaland motion in a global reference frame detected from GEODYSSEA GPS measurements: Implications for relative motions at its boundaries with the Australo-Indian plates and the South China block, in The Geodynamics of S and SE Asia (GEODYSSEA) Project, edited by P. Wilson and G. W. Michel, Scientific Technical Report 98/14, pp. 39-74, Potsdam, 1998.

Davies, P., Polyhedron assembly at Newcastle, method and initial result, Proc. IGS 1996 Analysis Center Workshop, edited by R. E. Neilan, P. A. vanScoy, and J. F. Zumberge, pp. 131-143, JPL, Pasadena, USA, 1997.

DeMets, C., R. G. Gordon, D. F. Argus, and S. Stein, Effect of recent revisions to the geomagnetic reversal timescale on estimates of current plate motions, Geophys. Res. Lett., 21, 2191-2194, 1994.

Duquesnoy, T., E. Barrier, M. Kasser, M. Aurelio, R. Gaulon, R. S. Punongbayan, C. Rangin, and the French-Philippine Cooperation Team, Detection of creep along the Philippine Fault: First results of geodetic measurements on Leyte island, central Philippine, Geophys. Res. Lett., 21, 975-978, 1994.

International GPS Service for Geodynamics, IGS Electronic Mail, Message No. 2071, IGS Central Bureau, Jet Propulsion Laboratory, California Institute of Technology, Pasadena, California, U.S.A., 1998.
King, R. W. and Y. Bock, Documentation for the MIT GPS analysis software, GAMIT, Massachussetts Institute of Technology, Cambridge, 1993.

Luton, G., J. Dawson, R. Govind, and D. Sproule, APRGP97 observation campaign overview, Proceedings of the Workshop on Regional Geodetic Network, Canberra, Australia, July 2-4, 1998, edited by AUSLIG, pp. 23 24, Canberra, 1998.

Michel, G. W., D. Angermann, P. Wilson, C. Reigber, and J. Klotz, Transient versus secular motion: the possible impact of earthquakes and interseismic loading on the GEODYSSEA site motions, in The Geodynamics of $S$ and SE Asia (GEODYSSEA) Project, edited by P. Wilson and G. W. Michel, Scientific Technical Report 98/14, pp. 75-97, Potsdam, 1998.

Michel, G. W., M. Becker, D. Angermann, C. Reigber, and E. Reinhart, Crustal motion in E- and SE-Asia from GPS measurements, Earth Planets Space, 52, this issue, 713-720, 2000.

Noll, C., http: //www. cddisa.gsfc.nasa.gov/cddis_welcome. html, CDDIS Global Data Center, 2000.

Prawirodirdjo, I., Y. Bock, R. McCaffrey, J. Genrich, E. Calais, C. Stevens, S. S. Puntodewo, C. Surabarya, J. Rais, and P. Zwick, Geodetic observations of interseismic strain segmentation at the Sumatra subduction zone, Geophys. Res. Lett., 24, 2601-2604, 1997.

Puntodewo, S. S., R. McCaffrey, E. Calais, Y. Bock, J. Rais, C. Subarya, R. Poewariardi, C. Stevens, J. Genrich, P. Zwick, and S. Wdowinski, GPS measurements of crustal deformation within the Pacific-Australia plate boundary zone in Irian Jaya, Tectonophys., 237, 141-153, 1994.

Rangin, C., L. Jolivet, M. Pubellier, and the Tethys Pacific Working Group, A simple model for the tectonic evolution of South-East Asia and the Indonesian region for the past 43 my, Bull. Soc. Geol. Fr., 6, 889-905, 1990.

Reinking, J., D. Angermann, and J. Klotz, Zur Anlage und Beobachtung gross-räumiger GPS-Netze fuer geodynamische Untersuchungen, Allg. Vermessungsnachrichten, 6/95, H. Wichmann Verlag, 1995.

Rothacher, M. and G. Mader, Combination of Antenna Phase Center Offsets and Variations: Antenna Calibration set IGS_01, IGS Central Bureau/University of Berne, Bern, Schweiz, 1996.

Rothacher, M. and L. Mervart, Bernese GPS Software Version 4.0, Astronomical Institute, University of Berne, Bern, 1996.

Sillard, P., Z. Altamimi, and C. Boucher, The ITRF96 realization and its associated velocity field, Geophys. Res. Let., 25, 3223-3226, 1998.

Simons, W. J. F., D. van Loon, A. Walpersdorf, B. A. C. Ambrosius, J. Kahar, H. Z. Abidin, D. A. Sarsito, C. Vigny, S. Haji Abu, and P. Morgan, Geodynamics of S.E. Asia: First results of the Sulawesi 1998 GPS campaign, in Geodesy beyond 2000_The Challenges of the First Decade, edited by K. P. Schwarz, International Association of Geodesy Symposia, 121, 271-277, Springer-Verlag, Berlin, Heidelberg, 2000

Simons, W. J. F., D. Angermann, B. A. C. Ambrosius, M. Becker, R. Noomen, A. Walpersdorf, P. Wilson, and C. Vigny, The final geodetic results of the GEODYSSEA project: the combined solution, in The Geodynamics of S and SE Asia (GEODYSSEA) Project, edited by P. Wilson and G. W. Michel, Scientific Technical Report 98/14, pp. 27-38, Potsdam, 1998.

Simons, W. J. F., B. A. C. Ambrosius, R. Noomen, D. Angermann, P. Wilson, M. Becker, E. Reinhart, A. Walpersdorf, and C. Vigny, Observing plate motions in S.E. Asia: Geodetic results of the GEODYSSEA project, Geophys. Res. Let., 26, 2081-2084, 1999.

Tregoning, P., F. K. Brunner, Y. Bock, S. S. Puntodewo, R. McCaffrey, J. F. Genrich, E. Calais, J. Rais, and C. Subarya, First geodetic measurement of convergence across the Java trench, Geophys. Res. Lett., 21, 2135-2138, 1994

Walpersdorf, A., C. Vigny, W. Simons, C. Subarya, and P. Manurung, Geodätische Bestimmung der Bewegungsraten an der Palu-Koro Verwerfung in Sulawesi, Zeitschr. f. Verm. Wesen, 125/3, 99-105, 2000.

Wilson, P., J. Rais, C. Reigber, E. Reinhart, B. A. C. Ambrosius, X. LePichon, M. Kasser, P. Suharto, A. Majid, P. Awang, R. Almeda, and C Boonphakdee, Study provides data on active plate tectonics in South-East Asia region, EOS Trans. AGU, 79(45), 545-549, 1998.

Wilson, P., G. Michel, and J. Rais, Das Projekt GEODYSSEA, Zeitschr. f. Verm. Wesen, 125/3, 70-74, 2000.

M. Becker (e-mail: becker@ifag.de), E. Reinhart, S. B. Nordin, D. Angermann, G. Michel, and C. Reigber 